\title{
A randomized, double-blind, placebo-controlled noninferiority trial of amoxicillin for clinically diagnosed acute otitis media in children 6 months to 5 years of age
}

\author{
Nicole Le Saux, Isabelle Gaboury, Marian Baird, Terry P. Klassen, Johnna MacCormick, \\ Colline Blanchard, Carrol Pitters, Margaret Sampson, David Moher
}

Abstract

Objectives: Debate continues with respect to a "watch and wait" approach versus immediate antibiotic treatment for the initial treatment of acute otitis media. In this double-blind noninferiority trial, we compared clinical improvement rates at 14 days for children (6 months to 5 years of age) with acute otitis media who were randomly assigned to receive amoxicillin or placebo.

Methods: We enrolled healthy children who presented to clinics or the emergency department with a new episode of acute otitis media during the fall and winter months in Ottawa (from December 1999 to the end of March 2002). The children were randomly assigned to receive amoxicillin (60 mg/kg daily) or placebo for 10 days. Telephone follow-up was performed on each of days 1,2 and 3 and once between day 10 and day 14 . The primary outcome was clinical resolution of symptoms, defined as absence of receipt of an antimicrobial (other than the amoxicillin in the treatment group) at any time during the 14-day period. Secondary outcomes were the presence of pain and fever and the activity level in the first 3 days, recurrence rates, and the presence of middle ear effusion at 1 and 3 months.

Results: According to clinical scoring, 415 of the 512 children who could be evaluated had moderate disease. At 14 days $84.2 \%$ of the children receiving placebo and $92.8 \%$ of those receiving amoxicillin had clinical resolution of symptoms (absolute difference $-8.6 \%$, $95 \%$ confidence interval $-14.4 \%$ to $-3.0 \%$ ). Children who received placebo had more pain and fever in the first 2 days. There were no statistical differences in adverse events between the 2 groups, nor were there any significant differences in recurrence rates or middle ear effusion at 1 and 3 months.

Interpretation: Our results did not support the hypothesis that placebo was noninferior to amoxicillin (i.e., that the 14-day cure rates among children with clinically diagnosed acute otitis media would not be substantially worse in the placebo group than the treatment group). Nevertheless, delaying treatment was associated with resolution of clinical signs and symptoms in most of the children.

CMA/ 2005;172(3):335-41
$M$ ore than half of all children experience at least 1 episode of acute otitis media before the age of 3 years. The incidence of this type of infection is highest among children under 2 years of age and appears to have increased since the $1970 \mathrm{~s}^{1-3}$ The issues of increasing antimicrobial resistance and the purported favourable natural history of untreated acute otitis media have sustained the debate over whether antimicrobial therapy should be given immediately or if "watchful waiting" would substantially alter outcomes for clinically diagnosed acute otitis media. Proponents of the "watch and wait" approach have argued that viruses are initially responsible for most clinical episodes. ${ }^{46}$ Large clinical trials have demonstrated that antimicrobials do provide a modest clinical benefit ${ }^{7-9}$ and that eradication of bacterial pathogens in the middle ear is associated with clinical success. ${ }^{10}$ To reconcile both points of view it could be reasoned that, despite the modest clinical benefit, early treatment of all episodes might not be justified., ${ }^{411-15}$ As outlined by Takata and Chan and their respective coauthors, ${ }^{16,17}$ many trials have suffered from a lack of description of excluded patients, multiple clinical definitions and different outcomes, all of which might have led to bias in interpretation.

We hypothesized that, given adequate control of pain and fever, the clinical success rate at 14 days among children 6 months to 5 years of age with clinically diagnosed acute otitis media who were given placebo would not be inferior to clinical resolution rates obtained with amoxicillin treatment. The secondary outcomes were short-term relief of symptoms such as pain and fever and presence of middle ear fluid at 1 and 3 months after diagnosis.

\section{Methods}

This randomized, double-blind, placebo-controlled noninferiority trial was conducted from November to March each winter between December 1999 and March 2002. Children at least 6 months old but less than 6 years of age were eligible if they pre- 
sented with new onset (less than 4 days) of symptoms referable to the upper respiratory tract and either ear pain or fever (temperature above $38^{\circ} \mathrm{C}$ ). In addition, all patients had to have evidence of middle ear effusion, defined as 2 or more of the following signs: opacity, impaired mobility on the basis of pneumatic otoscopy, and redness or bulging (or both) of the tympanic membrane. To determine perceived severity of disease, we used the only published clinical otitis score. ${ }^{10}$ Physicians had not previously been trained to use the scoring system but were asked to estimate the severity in each category using a table with scoring criteria listed. Scoring was based on temperature (scoring for temperature: $0=$ temperature less than $38^{\circ} \mathrm{C}, 1=$ temperature $38.0-38.5^{\circ} \mathrm{C}, 2=$ temperature $38.6-39^{\circ} \mathrm{C}, 3=$ temperature above $39^{\circ} \mathrm{C}$ ) and irritability, ear tugging, and redness and bulging of the tympanic membrane (scoring for other signs and symptoms: $0=$ absent, $1=$ mild, 2 = moderate, 3 = severe). An episode was defined as mild if the score at enrollment was less than 3 , moderate if the score was 3 to 7 and severe if it was 8 to 15 .

Potential subjects were excluded if they had allergy to penicillin or amoxicillin or sensitivity to ibuprofen or aspirin; if they had received antimicrobial treatment in the preceding 14 days; if they had any clinical suspicion of sepsis or mastoiditis; and if they had otorrhea, comorbid disease such as sinusitis or pneumonia, prior middle ear surgery, placement of a ventilation tube, history of recurrent acute otitis media (more than 4 episodes in 12 months), compromised immunity, craniofacial abnormalities, or any chronic or genetic disorder.

The Research Ethics Committee of the Children's Hospital of Eastern Ontario (CHEO) approved the study protocol. A parent or guardian gave written informed consent for each child before enrollment. Children were recruited at 3 sites in Ottawa: CHEO's Emergency Department (staffed by pediatricians and family practitioners), the Orleans Urgent Care Center (staffed by physicians trained in emergency medicine) and a local pediatric office (staffed by 5 pediatricians). Standardization of diagnostic criteria was not tested before the study. The conjugated pneumococcal vaccine was marketed in Canada starting in June 2001; however, during the remaining 5 months of study time (November 2001 to March 2002), this vaccine was not provided within the routine immunization schedule in Ontario.

The amoxicillin and a placebo with similar appearance and taste were dispensed in identical opaque bottles, which were numbered sequentially. The computer-generated randomization sequence, stratified by study centre and age ( 6 months to 2 years and 2 to 5 years), used random-permuted blocks of sizes 4 and 6 . To adequately conceal allocation, the randomization sequence was kept under secure conditions and was accessible only to the trial pharmacist (C.B.). The investigative team and parents were blinded to medication group throughout the study.

Each child received either amoxicillin suspension $(60 \mathrm{mg} / \mathrm{kg}$ daily) or placebo in 3 divided doses for 10 days. This dose of the study drug was selected on the following basis. Because the doses were approximated (as millilitres of suspension) by the research assistants at the time of enrollment, we wanted to avoid underdosing. Conversely, because we excluded children with recurrent acute otitis media, we felt that a higher dose of the study drug was unnecessary. Parents were also given a 5-day supply of antipyretic and analgesic medication in the form of ibuprofen suspension (Children's Advil) (5 mg/kg per dose if body weight less than 10 $\mathrm{kg}, 10 \mathrm{mg} / \mathrm{kg}$ per dose if over $10 \mathrm{~kg}$ ) to be given every 8 hours as required for pain or fever, and a 48-hour supply of codeine elixir $(1 \mathrm{mg} / \mathrm{kg})$ to be given as required for pain and fever.
The parent or guardian was contacted on days 1, 2 and 3 after randomization and once between day 10 and day 14 for administration of a standard questionnaire. On the first 3 days, parents were questioned about fever, irritability, appetite, ear drainage, sleeping patterns and activities. If the parent, guardian or research assistant felt that the symptoms were not improving or were worsening, a medical reassessment was advised, and the child was seen by a physician in the emergency department or clinic or by the pediatrician. If the parent or guardian felt that the child was generally improving, no reassessment was requested. The child was clinically assessed at 1 month and 3 months after randomization to determine the number of subsequent episodes of acute otitis media and to undergo tympanometry.

The primary outcome measure was clinical resolution of symptoms, defined as absence of receipt of an antimicrobial (other than the amoxicillin in the treatment group) at any time during the 14-day period, since prescription of an antimicrobial would be a clear marker of lack of improvement in the child's condition. The initiation of antimicrobial therapy was based on persistence or worsening of symptoms, fever or irritability associated with otoscopic signs of unresolving acute otitis media, or development of signs or symptoms indicative of mastoiditis or invasive disease. The decision to start antimicrobials was at the discretion of the physician who reassessed the patient because of the persistent symptoms. The secondary outcomes included presence of fever and activity levels on days 1, 2 and 3. Occurrence of any rash or diarrhea in the 14 days after randomization was also ascertained. The presence of middle ear effusion was assessed by tympanometry, as described below, 1 and 3 months after diagnosis.

Tympanometry was performed by trained research nurses. A handheld tympanometer was applied to make a seal at the external auditory canal. A graph and pressure measurement were then printed out and placed in a sealed envelope. Tympanometry was performed at enrollment and at 1 and 3 months after diagnosis. A pediatric otolaryngologist (J.M.), who was blinded as to treatment group and clinical course, read all of the tympanograms. A tympanogram was classified as abnormal if the static admittance was less than 0.2 mmho (type B curve) or if the tympanic peak pressure (TPP) was less than $-139 \mathrm{daPa}$ (decapascals, $1.0 \mathrm{daPa}=10 \mathrm{~Pa}=$ $1.02 \mathrm{~mm} \mathrm{H}_{2} \mathrm{O}$ ) or greater than $+11 \mathrm{daPa}$. A type A curve (static admittance of 0.2 mmho or more, TPP between -139 and $+11 \mathrm{daPa}$ ) was interpreted as normal. ${ }^{18}$ If a tympanogram was not interpretable, the data were classified as missing.

In traditional hypothesis-testing approaches, the research hypothesis states that 2 interventions differ; in contrast, in a noninferiority study, the research hypothesis is that one intervention is not clinically inferior to the other. This requires prior specification of a difference large enough to clinically favour the standard intervention over the study intervention. The study intervention is then declared noninferior to the standard intervention if the confidence interval (CI) comparing them covers only values that are smaller than this prespecified amount (called the margin of noninferiority). ${ }^{19} \mathrm{Be}-$ fore the study, a survey of local emergency physicians indicated that a difference of $10 \%$ would be acceptable to prove the noninferiority of placebo relative to amoxicillin. Calculation of the sample size to demonstrate noninferiority of placebo was therefore based on a maximum difference of $10 \%$ between the 2 groups and a clinical improvement rate of at least $80 \%$ in both groups. For a power of $90 \%$ and a type I error of $10 \%$, the sample size necessary to detect noninferiority between the interventions was 211 children per group, to which we added $25 \%$ for dropouts; we therefore needed a total of 528 children in the study. ${ }^{19}$ 
Although the subjects were stratified by age, we did not plan a priori to stratify the analysis on the basis of age. However, other studies conducted since the trial was initiated suggested that response rates could differ between children younger and older than 2 years of age..$^{15,17,20} \mathrm{In}$ an attempt to reflect these findings, we decided, before conducting the statistical analysis, to also analyze the data separately for each age group. For noninferiority trials, it is not clear whether a per-protocol analysis (eliminating patients lost to follow-up) or an intention-to-treat analysis (including all randomized patients) is more appropriate, ${ }^{19}$ especially in a situation such as this, where the outcome of patients lost to follow-up is unknown (and hence it is not clear which way any bias would operate) and where the study drug is not the prime reason for dropping out of the study. Data were therefore analyzed on both a per-protocol and an intention-to-treat basis.

The differences in clinical improvement rates and their 95\% CIs were calculated by means of the Wilson score method. ${ }^{21}$ Categorical secondary outcomes such as presence of fever and ability to perform usual activities were analyzed by $\chi^{2}$ tests with Yates's continuity correction or Fisher's exact test. Differences in the numbers of analgesic and codeine doses were assessed with a Poisson regression model. Numbers needed to treat and their $95 \%$ CIs were generated by the Wilson score method.22 A subgroup analysis was conducted with the subset of patients who had definitive evidence of middle ear fluid (type B curve) on the basis of tympanometry at baseline. All reported $p$ values for secondary outcomes are 2-sided; differences were declared statistically significant if the $p$ value was 0.048 or less (because of adjustment for one interim analysis).

\section{Results}

Recruitment took place from Dec. 8, 1999, to Mar. 30, 2000, from Nov. 30, 2000, to Apr. 1, 2001, and from Nov. 30, 2001, to Mar. 30, 2002, a total of 14 months. A planned interim analysis regarding the primary outcome and safety data was conducted after 176 children had been enrolled and had completed the 3-month follow-up. The O'Brien and Fleming criterion was used to statistically assess early efficacy of the treatments. ${ }^{23}$ The results at that time were inconclusive, and the trial continued to the planned recruitment target. Of 1924 children screened, 963 met the eligibility criteria. Of these, 531 (55.1\%) proceeded to randomization (Fig. 1). Nineteen children were excluded because of post hoc determination of an alternative diagnosis or because of inappropriate randomization. Therefore, 512 children (191 children 6 to 23 months of age and 321 children 2 to 5 years of age) were included in the data analysis (Fig. 1). There were no substantial differences in baseline characteristics between the 2 study groups (Table 1). On the basis of previously published clinical scoring criteria, ${ }^{10} 29$ children $(5.7 \%)$ had mild otitis media, $415(81.1 \%)$ had moderate disease, and $68(13.3 \%)$ had severe disease. There were no statistically significant differences in proportions of children in each severity category between the 2 treatment groups or between the 2 age groups.

In the per-protocol analysis, the clinical resolution rates for all children at 14 days were $84.2 \%$ for the placebo group and $92.8 \%$ for the amoxicillin group, an absolute difference in resolution rates of $-8.6 \%$ (95\% CI $-14.4 \%$ to $-3.0 \%$ ) (Table 2). In the intention-to-treat analysis, the clinical resolution rates were $79.5 \%$ for the placebo group and $89.9 \%$ for the amoxicillin group, an absolute difference of $-10.4 \%$ overall $(-5.6 \%$ for children 6 to 23 months of age and $-13.0 \%$ for children 2 to 5 years of age). For children within the placebo group who eventually received an antimicrobial, the reassessment leading to prescription of the drug occurred in the first 3 days for two-thirds of subjects and between 4 and 14 days for the remaining third (data not shown). The average number of children needed to treat to prevent 1 failure within 14 days $^{24}$ was 11.0 (95\% CI 6.83-30.0) for all subjects.

Overall, more children in the placebo group had fever and pain in the first 2 days (Table 3). There were no significant differences among children 6 to 23 months of age with respect to duration of fever or analgesic consumption in the first 3 days; however, among children 2 to 5 years of age, those who received placebo were more likely to have fever and pain, and they received significantly more ibuprofen and codeine (on day 3 only) than children who were given amoxicillin (data not shown). The number of days on which the children could not participate in regular activities was the same regardless of age group. There were no statistically significant differences in the frequency of middle ear fluid: at 1 month, $77 / 222(34.7 \%)$ in the placebo group v. $68 / 233(29.2 \%)$ in the amoxicillin group $(p=0.23)$; at 3 months, $47 / 210(22.4 \%)$ v. $58 / 228(25.4 \%)(p=0.50)$. Similarly, there were no statistically significant differences in the rates of recurrence of clinical otitis media: at 1 month, $39 / 236(16.5 \%)$ in the placebo group v. $27 / 248(10.9 \%)$ in the amoxicillin group $(p=0.08)$; at 3 months, $45 / 229$ $(19.7 \%)$ v. $44 / 242(18.2 \%)(p=0.73)$.

Among children 6 to 23 months of age, there were no statistically significant differences in the occurrence of adverse effects: for diarrhea, $17 / 92(18.5 \%)$ in placebo group v. $20 / 89(22.5 \%)$ in the amoxicillin group $(p=0.80)$; for rash, $9 / 92(9.8 \%)$ v. $13 / 89(14.6 \%)(p=0.37)$. Similarly, among children 2 to 5 years, there were no statistically significant differences in the occurrence of these adverse effects: for diarrhea, $10 / 148(6.8 \%)$ v. $6 / 146(4.1 \%)(p=0.58)$; for rash, $11 / 148(7.4 \%)$ v. $4 / 146(2.7 \%)(p=0.742)$. No child had to discontinue medication because of diarrhea.

Overall, $316(61.7 \%)$ of the children had middle ear effusion documented by handheld tympanometer readings. The symptom resolution rates at 14 days among children with type B tympanogram at enrollment were as follows: among those who received placebo, 112/135 (83.0\%) overall, $45 / 54$ $(83.3 \%)$ in those 6 to 23 months of age and $67 / 81$ (82.7\%) in those 2 to 5 years of age; among those who received amoxicillin, 150/161 (93.2\%) overall, 54/62 (87.1\%) in those 6 to 23 months of age and 96/99 (97.0\%) in those 2 to 5 years of age. The absolute difference between the placebo and amoxicillin groups was $-10.2 \%$ (95\% CI $-18.0 \%$ to $-2.8 \%$ ) overall, $-3.8 \%$ (95\% CI $-17.3 \%$ to $9.3 \%)$ for those 
6 to 23 months of age and $-14.3 \%$ (95\% CI $-24.1 \%$ to $-5.6 \%)$ for those 2 to 5 years of age. The odds ratios (ORs) for clinical resolution in the amoxicillin group relative to the placebo group were 2.8 (95\% CI 1.31-5.98) overall, 1.35 (95\% CI 0.48-3.79) for children 6 to 23 months of age and 6.69 (95\% CI 1.85-24.18) for children 2 to 5 years of age.
Of 490 parents or guardians who were available for the 2 -week follow-up, 28 were not familiar enough with the medication to provide an opinion about the group to which their child had been assigned. Of the remaining 462, 280 caregivers $(60.6 \%)$ were unsure of the randomization group. Thirty-two $(42.7 \%)$ of the 75 parents in the anti-

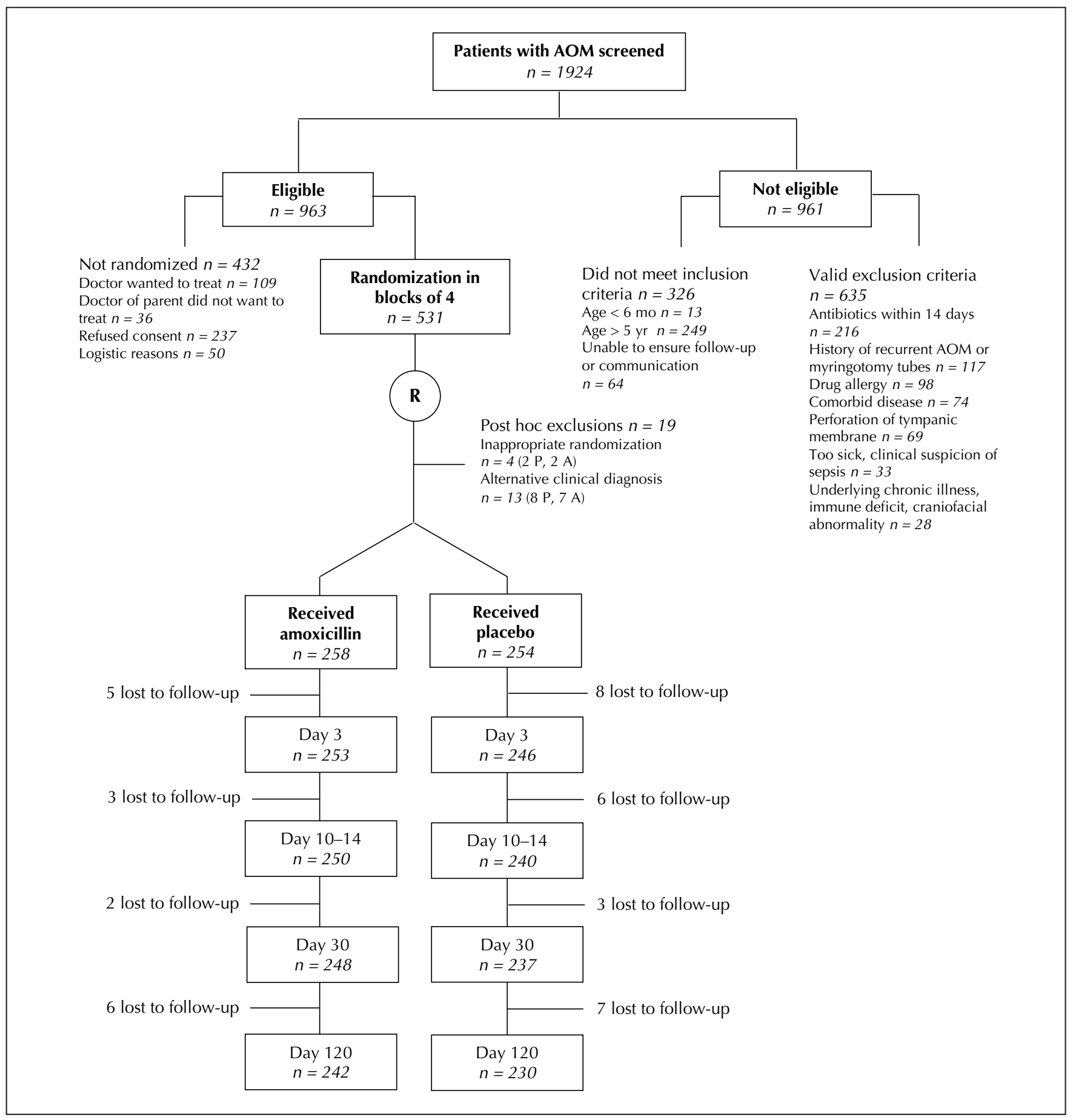

Fig. 1: Flow of patients through the trial. $A O M=$ acute otitis media, $R=$ randomization, $P=$ placebo, $A=$ amoxicillin. For patients with valid exclusion criteria, drug allergy refers to allergies to amoxicillin, penicillin or codeine, and comorbid conditions of interest were pneumonia and sinusitis. 
biotic group and $45(42.1 \%)$ of the 107 in the placebo group incorrectly identified the group assignment $(p=$ $0.94)$. These results suggest that blinding was successful. Although compliance was stressed during follow-up telephone calls made in the first 3 days after enrollment, only one-third of the caregivers brought medication bottles back at the 1-month follow-up; hence, specific rates of compliance could not be determined.

\section{Interpretation}

This study is one of the largest randomized controlled trials reported for the treatment of acute otitis media in children under 6 years of age. We chose a clinical definition of acute otitis media as the entry criterion and accepted a physician's clinical diagnosis of failure. Accurate prediction of bacterial causality based on clinical examination alone is difficult, ${ }^{25,26}$ and tympanocentesis is not commonly performed for routine cases of acute otitis media. ${ }^{27}$ Nonresolution of symptoms at 14 days is likely to represent a true clinical or bacteriologic failure and is less likely to

\section{Table 1: Baseline characteristics of children 6 months to 5 years of age seen in the emergency department for acute otitis media}

\begin{tabular}{|c|c|c|}
\hline \multirow[b]{2}{*}{ Characteristic } & \multicolumn{2}{|c|}{ Group; no. (and \%) of patients* } \\
\hline & $\begin{array}{c}\text { Amoxicillin } \\
n=258\end{array}$ & $\begin{array}{l}\text { Placebo } \\
n=254\end{array}$ \\
\hline \multicolumn{3}{|l|}{ Demographic } \\
\hline Age, mean (and SD), yr & $3.00(1.61)$ & $2.87(1.59)$ \\
\hline No. of males & $129(50.0)$ & $132(52.0)$ \\
\hline \multicolumn{3}{|l|}{ Clinical } \\
\hline Clinical score, mean (and SD) & $5.23(1.82)$ & $5.33(1.84)$ \\
\hline Clear nasal discharge & $187(72.5)$ & $196(77.2)$ \\
\hline Coloured thick nasal discharge & $98(38.0)$ & $97(38.2)$ \\
\hline Presence of cough & $206(79.8)$ & $207(81.5)$ \\
\hline Ear pain or crying & $226(87.6)$ & $216(85.0)$ \\
\hline Fever & $162(62.8)$ & $164(64.6)$ \\
\hline Unilateral otitis media & $180(69.8)$ & $181(71.2)$ \\
\hline \multicolumn{3}{|l|}{ Tympanic } \\
\hline "Bulging" tympanic membrane & $192(74.4)$ & $177(69.7)$ \\
\hline Type B curve (abnormal) & $169(65.5)$ & $147(57.9)$ \\
\hline Type A curve (normal)† & $78(30.2)$ & $89(35.0)$ \\
\hline Uninterpretable & $3(1.2)$ & $6(2.4)$ \\
\hline \multicolumn{3}{|l|}{ Other } \\
\hline Attends group child care setting & $109(42.2)$ & $121(47.6)$ \\
\hline $\begin{array}{l}\text { No. of siblings at home, median } \\
\text { (and range) }\end{array}$ & $1(0-6)$ & $1(0-4)$ \\
\hline $\begin{array}{l}\text { Received current influenza } \\
\text { vaccine }\end{array}$ & $42(16.2)$ & $33(13.0)$ \\
\hline $\begin{array}{l}\text { Exposed to smokers in home or } \\
\text { child care setting }\end{array}$ & $68(26.3)$ & $67(26.4)$ \\
\hline
\end{tabular}

represent persistent viral symptoms or a new infection. ${ }^{28}$ Consistent with prior reports of overdiagnosis, ${ }^{29,30}$ only $60 \%-70 \%$ children who had a clinical diagnosis of acute otitis media had tympanogram readings (obtained with a handheld tympanometer) that supported the presence of middle ear fluid.

Among children 6 months to 5 years of age and those 2 to 5 years of age, amoxicillin had a modest treatment advantage over placebo (absolute difference of $8.6 \%$ and $9.7 \%$ respectively) in terms of clinical resolution rates at 14 days. In children 2 to 5 years, presence of middle ear fluid documented by tympanometry predicted a greater likelihood of success of antimicrobial therapy (OR 6.7, 95\% CI 1.85-24.18). ${ }^{9,31}$ There were no appreciable differences in terms of adverse events or significant morbidity, apart from higher consumption of analgesia in 2- to 5-year-old children who received placebo.

A subgroup analysis was conducted on the basis of age, although its findings are less robust, given the smaller numbers of children per group. In general, children 6 to 23 months of age had lower clinical resolution rates $(79.3 \%$ with placebo and $85.4 \%$ with amoxicillin) than older children $(87.2 \%$ and $96.9 \%$ respectively), but the difference between placebo and amoxicillin was smaller $(6.1 \%$ for younger children, $9.7 \%$ for older children). This may reflect greater diagnostic uncertainty or a greater proportion of subjects with viral causes of acute otitis media in the younger age group; alternatively, the older children may have presented at a later stage of disease, when a larger proportion had secondary bacterial otitis manifesting with more pain and crying. ${ }^{32,33}$ Through our analysis, we could not identify other characteristics to predict those who experienced spontaneous resolution.

The overall clinical resolution rate for the placebo group $(84.2 \%)$ was comparable to estimated rates in previous trials and systematic reviews. ${ }^{4,8,16}$ A recent trial involving children less than 2 years of age, conducted in the Netherlands, demonstrated differences in treatment failure between placebo and amoxicillin of $9 \% .{ }^{15}$ In that study, 64\%-70\% of the children in both groups had persistent symptoms at day $11 .{ }^{15}$ Other reports for children under 2 years of age have also documented failure rates of $15 \%$ despite treatment with antimicrobials. ${ }^{9,34,35}$ In the current study, children between 2 and 5 years of age had higher clinical resolution rates $(87.2 \%$ and $96.9 \%)$ with larger absolute differences

Table 2: Cumulative clinical resolution rates in the per-protocol analysis at 14 days

\begin{tabular}{|c|c|c|c|}
\hline \multirow[b]{2}{*}{ Age group } & \multicolumn{2}{|c|}{ Group; no. (and \%) of patients } & \multirow{2}{*}{$\begin{array}{l}\text { Absolute difference, \% } \\
\quad \text { (and 95\% Cl) }\end{array}$} \\
\hline & Amoxicillin & Placebo & \\
\hline All children & $232 / 250(92.8)$ & $202 / 240(84.2)$ & $-8.6(-14.4$ to -3.0$)$ \\
\hline $6-23 \mathrm{mo}$ & $76 / 89(85.4)$ & 73/92 (79.3) & $-6.1(-17.1$ to 5.2$)$ \\
\hline $2-5 \mathrm{yr}$ & 156/161 (96.9) & 129/148 (87.2) & $-9.7(-16.3$ to -3.8$)$ \\
\hline
\end{tabular}

Note: $\mathrm{Cl}=$ confidence interval. 
(9.7\%) between placebo and amoxicillin, which may reflect a higher degree of certainty in diagnosis of bacterial acute otitis media in this age group. Another placebo-controlled trial reported a 5\% absolute difference among children over 2 years of age and a $3.3 \%$ difference among those under 2 years of age. 'That study differed from ours in that analgesia was not routinely prescribed, and patient recruitment methods were not described in detail.?

Of the children who met the eligibility criteria, only half were recruited for randomization. ${ }^{36} \mathrm{We}$ documented reasons stated for nonparticipation, but we did not record other criteria such as past history, other parental factors or subtle clinical factors that might have led to bias in the subjects enrolled. Although subjective clinical diagnosis is a standard of care, it also represented a limitation in this trial

\section{Table 3: Presence of pain and fever and number of doses of analgesic (ibuprofen or acetominophen) and codeine over first 3 days}

\begin{tabular}{|c|c|c|c|}
\hline \multirow[b]{2}{*}{ Symptom or treatment } & \multicolumn{2}{|c|}{ Group; no. (and \%) of patients* } & \multirow[b]{2}{*}{$p$ value } \\
\hline & Amoxicillin & Placebo & \\
\hline \multicolumn{4}{|l|}{ Fever } \\
\hline Day 1 & $74 / 258(28.7)$ & $97 / 254(38.2)$ & 0.022 \\
\hline Day 2 & $37 / 254(14.6)$ & $78 / 250(31.2)$ & $<0.001$ \\
\hline Day 3 & $29 / 253(11.5)$ & $45 / 246(18.3)$ & 0.030 \\
\hline \multicolumn{4}{|l|}{ Pain } \\
\hline Day 1 & $82 / 258(31.8)$ & $106 / 254(41.7)$ & 0.017 \\
\hline Day 2 & $56 / 254(22.0)$ & $83 / 250(33.2)$ & 0.005 \\
\hline Day 3 & $43 / 253(17.0)$ & $53 / 246(21.5)$ & 0.20 \\
\hline \multicolumn{4}{|l|}{ Irritability } \\
\hline Day 1 & $71 / 258(27.5)$ & $90 / 254(35.4)$ & 0.06 \\
\hline Day 2 & $54 / 254(21.3)$ & $70 / 250(28.0)$ & 0.07 \\
\hline Day 3 & $48 / 253(19.0)$ & $54 / 246(22.0)$ & 0.38 \\
\hline \multicolumn{4}{|l|}{ Vomiting } \\
\hline Day 1 & $19 / 258(7.4)$ & $29 / 254(11.4)$ & 0.12 \\
\hline Day 2 & $12 / 254(4.7)$ & $13 / 250(5.2)$ & 0.81 \\
\hline Day 3 & 9/253 (3.6) & 8/246 (3.3) & 0.86 \\
\hline \multicolumn{4}{|l|}{$\begin{array}{l}\text { No. of analgesic } \\
\text { doses, mean (and SD) } \dagger\end{array}$} \\
\hline Day 1 & $2.0(1.22)$ & $2.2(1.19)$ & 0.12 \\
\hline Day 2 & $1.4(1.18)$ & $1.7(1.30)$ & $<0.001$ \\
\hline Day 3 & $1.0(1.15)$ & $1.2(1.23)$ & 0.002 \\
\hline \multicolumn{4}{|l|}{$\begin{array}{l}\text { No. of codeine doses, } \\
\text { mean (and SD) } \dagger\end{array}$} \\
\hline Day 1 & $0.8(1.08)$ & $0.8(1.02)$ & 0.91 \\
\hline Day 2 & $0.4(0.86)$ & $0.5(0.86)$ & 0.55 \\
\hline Day 3 & $0.1(0.39)$ & $0.2(0.48)$ & 0.021 \\
\hline \multicolumn{4}{|l|}{$\begin{array}{l}\text { Able to do usual } \\
\text { activities }\end{array}$} \\
\hline Day 1 & 196/252 (77.8) & $174 / 248(70.2)$ & 0.052 \\
\hline Day 2 & $210 / 252(83.3)$ & $198 / 250(79.2)$ & 0.24 \\
\hline Day 3 & $223 / 250(89.2)$ & $208 / 245(84.9)$ & 0.15 \\
\hline
\end{tabular}

*Except where indicated otherwise.

tMean numbers of doses were calculated on the basis of the same numbers of children in each group on each day as for other symptoms (e.g., 258 on day 1, 254 on day 2 and 253 on day 3 for amoxicillin group). because it led to a significant degree of overdiagnosis. Exploration of other parameters to attempt differentiation of viral otitis from bacterial otitis might have been useful. ${ }^{37}$ Larger numbers of subjects, particularly in the younger age group, would have permitted more robust conclusions.

Our results did not support the research hypothesis that placebo was noninferior to amoxicillin and that rates of clinical resolution would not be substantially worse in the placebo group than the treatment group. Of note, however, most of the children who received placebo experienced resolution of clinical signs and symptoms. In addition to identifying factors that could predict the likelihood of success of antimicrobial therapy, a prospective study might help to identify children who are likely to experience spontaneous resolution.

This article has been peer reviewed.

From the Department of Pediatrics (Le Saux, Baird, Pitters, Moher), the Pharmacy Patient Service Unit (Blanchard) and the Division of Otolaryngology, Department of Surgery (MacCormick), Children's Hospital of Eastern Ontario, Ottawa, Ont.; the Chalmers Research Group, Children's Hospital of Eastern Ontario Research Institute, Ottawa, Ont. (Gaboury, Sampson, Moher); the Department of Epidemiology and Community Medicine, Faculty of Medicine, University of Ottawa, Ottawa, Ont. (Moher); and the Department of Pediatrics, University of Alberta, Edmonton, Alta. (Klassen).

Competing interests: None declared.

Contributors: Terry Klassen provided advice on the initial design and conduct of the study. David Moher helped with the original design and provided expert consultation on the conduct of the study, the content of the questionnaire and reporting of results. Marian Baird was the research coordinator and primary nurse responsible for the study. Margaret Sampson assisted in literature reviews and advised in the conduct of the study and its publication. Colline Blanchard was responsible for developing the placebo and directed the distribution of medications from the pharmacy. Johnna MacCormick read the tympanograms. Isabelle Gaboury performed the statistical analysis. Nicole Le Saux wrote the protocol, supervised the study and wrote the manuscript in close consultation with the other authors and acts as guarantor of the paper. All authors participated in revising the manuscript and approved the final version for submission.

Acknowledgements: We thank the children, their families and the physicians who participated in our study for their willingness to contribute to this research endeavour; Ba' Pham, who helped to develop the original statistical design; Dr. Martin Osmond, who contributed as a member of the steering committee for 24 months; and Drs. Dele Davies, James King and James Hutchison, who reviewed adverse events and the interim analysis as chair (D.D.) and members of the Data and Safety Monitoring Committee. Physician Services Incorporated provided support for study expenses. Whitehall Robbins provided ibuprofen (Children's Advil) free of charge and funded the tympanometers used in the study but was not involved in the design of the study or the analysis of the results.

\section{References}

1. Schappert SM. Office visits for otitis media: United States, 1975-90. Adv Data 1992;(214):1-19.

2. Joki-Erkkila VP, Laippala P, Pukander J. Increase in paediatric acute otitis media diagnosed by primary care in two Finnish municipalities: $1994-5$ versus 1978-9. Epidemiol Infect 1998;121(3):529-34.

3. Fleming DW, Cochi SL, Hightower AW, Broome CV. Childhood upper respiratory tract infections: To what degree is incidence affected by day-care attendance? Pediatrics 1987;79(1):55-60.

4. Del Mar C, Glasziou P, Hayem M. Are antibiotics indicated as initial treatment for children with acute otitis media? A meta-analysis. BM7 1997;314 (7093):1526-9.

5. Van Buchem FL, Peeters MF, van 't Hof MA. Acute otitis media: a new treatment strategy. $\operatorname{Br}$ Med 7 (Clin Res Ed) 1985;290(6474):1033-7.

6. Culpepper L, Froom J. Routine antimicrobial treatment of acute otitis media: Is it necessary? $7 A M A 1997 ; 278(20): 1643-5$.

7. Kaleida PH, Casselbrant ML, Rockette HE, Paradise JL, Bluestone CD, Blatter MM, et al. Amoxicillin or myringotomy or both for acute otitis media: results of a randomized clinical trial. Pediatrics 1991;87(4):466-74. 
8. Rosenfeld RM, Vertrees JE, Carr J, Cipolle RJ, Uden DL, Giebink GS, et al. Clinical efficacy of antimicrobial drugs for acute otitis media: metaanalysis of 5400 children from thirty-three randomized trials. 7 Pediatr 1994;124(3):355-67.

9. Cohen R, Levy C, Boucherat M, Langue J, de La Rocque F. A multicenter, randomized, double-blind trial of 5 versus 10 days of antibiotic therapy for acute otitis media in young children. 7 Pediatr 1998;133(5):634-9.

10. Dagan R, Leibovitz E, Greenberg D, Yagupsky P, Fliss DM, Leiberman A. Early eradication of pathogens from middle ear fluid during antibiotic treatment of acute otitis media is associated with improved clinical outcome. Pediatr Infect Dis 7 1998;17(9):776-82.

11. Cates C. An evidence based approach to reducing antibiotic use in children with acute otitis media: controlled before and after study. BM7 1999;318 (7185):715-6.

12. Little P, Gould C, Williamson I, Moore M, Warner G, Dunleavey J. Pragmatic randomised controlled trial of two prescribing strategies for childhood acute otitis media. BM7 2001;322(7282):336-42.

13. Leibovitz E, Greenberg D, Piglansky L, Raiz S, Porat N, Press J, et al. Recurrent acute otitis media occurring within one month from completion of antibiotic therapy: relationship to the original pathogen. Pediatr Infect Dis $\mathcal{F}$ 2003;22(3):209-16.

14. Froom J, Culpepper L, Grob P, Bartelds A, Bowers P, Bridges-Webb C, et al. Diagnosis and antibiotic treatment of acute otitis media: report from International Primary Care Network. BM7 1990;300(6724):582-6.

15. Damoiseaux RA, van Balen FA, Hoes AW, Verheij TJ, de Melker RA. Primary care based randomised, double blind trial of amoxicillin versus placebo for acute otitis media in children aged under 2 years. BM7 2000;320(7231):350-4.

16. Takata GS, Chan LS, Shekelle P, Morton SC, Mason W, Marcy SM. Evidence assessment of management of acute otitis media: I. The role of antibiotics in treatment of uncomplicated acute otitis media. Pediatrics 2001; 108(2):239-47.

17. Chan LS, Takata GS, Shekelle P, Morton SC, Mason W, Marcy SM. Evidence assessment of management of acute otitis media: II. Research gaps and priorities for future research. Pediatrics 2001;108(2):248-54.

18. Paradise JL, Smith CG, Bluestone CD. Tympanometric detection of middle ear effusion in infants and young children. Pediatrics 1976;58(2):198-210.

19. Jones B, Jarvis P, Lewis JA, Ebbutt AF. Trials to assess equivalence: the importance of rigorous methods. BM7 1996;313(7048):36-9.

20. Bain J. Treatment of acute otitis media: Are children entered into clinical trials representative? Br 7 Gen Pract 2001;51(463):132-3.

21. Newcombe RG. Two-sided confidence intervals for the single proportion: comparison of seven methods. Stat Med 1998;17(8):857-72.

22. Newcombe RG. Interval estimation for the difference between independent proportions: comparison of eleven methods. Stat Med 1998;17(8):873-90.
23. O'Brien PC, Fleming TR. A multiple testing procedure for clinical trials. Biometrics 1979;35:549-56.

24. Barrowman NJ. Missing the point (estimate)? Confidence intervals for the number needed to treat. CMAF 2002;166(13):1676-7.

25. McCormick DP, Lim-Melia E, Saeed K, Baldwin CD, Chonmaitree T. Otitis media: Can clinical findings predict bacterial or viral etiology? Pediatr Infect Dis 7 2000;19(3):256-8.

26. Rosenfeld RM. Diagnostic certainty for acute otitis media. Int 7 Pediatr Otorbinolaryngol 2002;64(2):89-95.

27. Palmu AA, Herva E, Savolainen H, Karma P, Makela PH, Kilpi TM. Association of clinical signs and symptoms with bacterial findings in acute otitis media. Clin Infect Dis 2004;38(2):234-42.

28. Dagan R, Leibovitz E. Bacterial eradication in the treatment of otitis media. Lancet Infect Dis 2002;2(10):593-604.

29. Pichichero ME. Changing the treatment paradigm for acute otitis media in children. 7AMA 1998;279(21):1748-50.

30. Pichichero ME. Diagnostic accuracy, tympanocentesis training performance, and antibiotic selection by pediatric residents in management of otitis media. Pediatrics 2002;110(6):1064-70.

31. Jacobs J, Springer DA, Crothers D. Homeopathic treatment of acute otitis media in children: a preliminary randomized placebo-controlled trial. Pediatr Infect Dis 7 2001;20(2):177-83.

32. Kontiokari T, Koivunen P, Niemela M, Pokka T, Uhari M. Symptoms of acute otitis media. Pediatr Infect Dis 7 1998;17(8):676-9.

33. Heikkinen T, Ruuskanen O. Signs and symptoms predicting acute otitis media. Arch Pediatr Adolesc Med 1995;149(1):26-9.

34. Harsten G, Prellner K, Heldrup J, Kalm O, Kornfalt R. Acute respiratory tract infections in children. A three-year follow-up from birth. Acta Paediatr Scand 1990;79(4):402-9.

35. Arola M, Ziegler T, Ruuskanen O. Respiratory virus infection as a cause of prolonged symptoms in acute otitis media. 7 Pediatr 1990;116(5):697-701.

36. Wald ER. Acute otitis media: more trouble with the evidence. Pediatr Infect Dis 7 2003;22(2):103-4.

37. Uhari M, Niemela M, Hietala J. Prediction of acute otitis media with symptoms and signs. Acta Paediatr 1995;84(1):90-2.

Correspondence to: Dr. Nicole Le Saux, Department of Infectious Diseases, Children's Hospital of Eastern Ontario, 401 Smyth Road, Ottawa ON K1H 8L1; fax 613-737-4832;

lesaux@cheo.on.ca

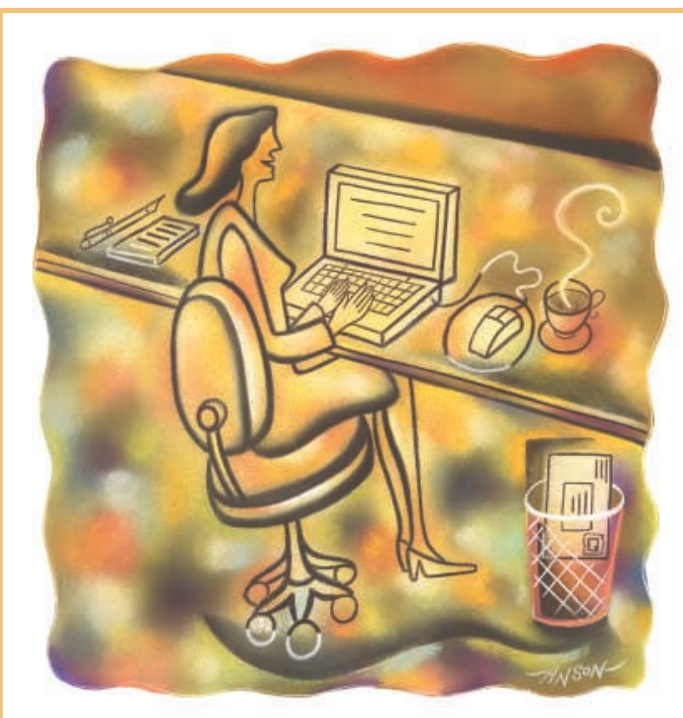

\title{
Online manuscript submissions and peer review
}

\author{
NOW AVAILABLE AT CMAJ \\ http://mc.manuscriptcentral.com/cmaj
}

